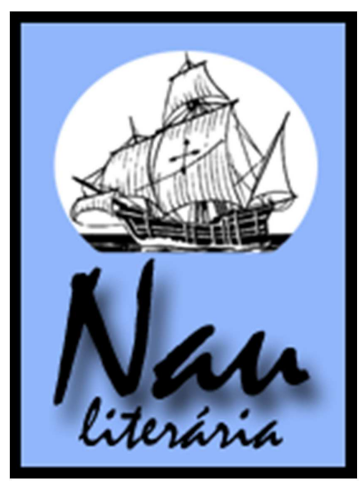

\title{
É possível uma outra vida na cidade moderna? Uma leitura de Outra vida, de Rodrigo Lacerda
}

\author{
Girvani José Sulzbacher Seitel ${ }^{*}$
}

\begin{abstract}
Resumo: Na modernidade, o romance é tecido sobre o conflituoso e ambíguo cenário da cidade que denota um espaço de contradições, pólo de atração e de repúdio, paradoxo entre utopia e inferno. Publicada em 2009, Outra vida, de Rodrigo Lacerda, insere-se neste contexto por trazer à luz da representação a cidade enquanto lócus de incerteza e imprevisibilidade. $\mathrm{O}$ estudo prende-se a uma análise da narrativa que dê enfoque à representação das imagens da cidade moderna, em especial aquelas que revelam a degradação, a alienação e a desumanização do sujeito.
\end{abstract}

Palavras-chave: Romance; Outra vida; cidade; imagens.

\begin{abstract}
In modernity, the novel is woven over the conflicting and ambiguous city scenery that denotes a place of contradictions, a pole of attraction and rejection, the paradox between utopia and hell. Published in 2009, Outra vida, by Rodrigo Lacerda, fits into this context by bringing to light the city's representation as a locus of uncertainty and unpredictability. The study concerns an analysis of the narrative that gives focus to the representation of images of the modern city, especially those that reveal the degradation, alienation and dehumanization of the subject.
\end{abstract}

Keywords: Romance; Outra vida; city; images.

\section{Descortinando o cenário da cidade}

A obra literária estabelece uma transcendência sobre a realidade, tecendo seu discurso pelas trilhas do imaginário. Os fatos chegam até o leitor como representação de algo que, por sua vez, problematiza a realidade histórica. No que tange ao romance, este é um fenômeno social, pois, resultante de convicções, crenças, códigos e costumes sociais, busca exprimir a sociedade. Paul Ricoeur (1983) descreve o discurso ficcional como sendo quase história, à medida que os acontecimentos relatados são fatos passados para a voz narrativa, como se tivessem realmente ocorrido.

Nesse sentido, o romance Outra vida (2009), de Rodrigo Lacerda, se revela como forma de representação que traduz magistralmente o percurso do sujeito em meio à cidade moderna. A narrativa constituiu um imaginário providencial para a realização do estranhamento da vida cotidiana citadina, uma vez que não busca necessariamente soluções, e sim reflexões sobre a experiência de choque que a conflituosa vida urbana imprime no sujeito.

\footnotetext{
* Graduado em Letras - Espanhol (URI). Pós-Graduação Lato sensu em Metodologia do Ensino de Português (URI). Mestrando em Literatura Comparada na Universidade Regional Integrada do Alto Uruguai e das Missões.
} 
Da analogia estabelecida entre literatura e cidade, quando "confere àquela seu valor de 'sintoma', de mutação de hábitos, de chamamento e aculturação às novas formas e viver citadinas" (PESAVENTO, 1999, p.14), Outra vida denuncia as formas de vida representadas na urbe contemporânea.

\section{Imagens da cidade em Outra vida}

[...] é uma das principais avenidas da cidade e estivera bastante movimentada durante todo o dia. Mas à medida que escurecia, a afluência ia aumentando aos poucos; e no momento em que todos os lampiões se iluminaram, duas densas e contínuas correntes de gente passavam apressadamente diante da porta. Nunca estivera, nesse momento particular do entardecer, numa situação semelhante, e o agitado mar de cabeças humanas enchia-me, pois, de uma emoção deliciosamente nova. Deixei de lado, afinal, qualquer preocupação com as coisas que se passavam dentro do hotel e concentrei-me na contemplação da cena do lado de fora. (POE, 2010, p.92)

A epígrafe é um excerto do ensaio O homem da multidão, de Edgar Allan Poe, em que o escritor narra as particularidades do sujeito que caminha em meio à multidão nas ruas de Londres no século XIX. Na descrição de Poe, estão caracterizado dois tipos de pessoas. Um tipo é o homem atarefado, com trajes elegantes e de olhar confiante, e quando empurrado por alguém que por ele passa, nenhum sintoma de impaciência se faz ver em seus olhos. Este é o homem de negócios, advogado, nobre, comerciante. O outro tipo que transita pelas ruas londrinas causa estranheza, pois caminha demasiadamente depressa; tem o rosto afogueado e fala e gesticula sozinho, como se sentisse solitário, ainda que mergulhado à multidão.

A referência ao texto de Poe é oportuna para que se discuta acerca da representação da vida do sujeito em meio à cidade moderna. Na literatura contemporânea, a desumanização é uma das temáticas que movem escritores na produção de obras que representam o esfacelamento das relações humanas dentro de uma sociedade reificada.

Em estudo recente, “A Forma do Real: a representação da cidade em Eles eram muitos cavalos", Rejane C. Rocha (2011) comenta que a narrativa contemporânea, voltada para apreensão do espaço urbano e das formas de sociabilidades, se constitui na orla de dois elementos. Segundo a autora, de um lado tem-se o objeto em si da representação: a urbe e sua realidade muitas vezes inapreensível e impossível de ser narrada, composta por um cotidiano de violência, de disparidades sociais e econômicas, de pequenas e grandes tragédias. De outro lado, tem-se a tradição literária que desde o princípio da modernidade, taxativamente escolheu o espaço urbano como fonte da qual os escritores extraem meios expressivos, como a velocidade, a multidão, a industrialização. 
Nesta direção, modernidade e experiência urbana formam um binômio de dupla implicação. Ao constituir como uma questão fundamental para os modernos, a cidade tornouse uma paisagem inevitável, pólo de atração e de repúdio, e, sobremaneira, um paradoxo de uma utopia e um inferno (cf. GOMES, 2000). Nesse contexto, o sujeito caminha em meio à multidão e tem a noção que caminha sobre um mundo em decadência e ruínas.

Ao passar por um longo processo de modernização, a cidade apresenta-se como uma imensa arena de signos gastos e dispersos, signos que fazem a ponte entre a própria urbe e o sujeito. Renato Cordeiro Gomes traça um panorama do desenvolvimento das cidades no Brasil. Segundo o crítico, este desenvolvimento se deu de modo contraditório, pois viu-se, em nível internacional, as mudanças radicais e velozes que colocaram em discussão as verdades da modernidade. Enquanto isso, no Brasil, verificou-se, a partir dos anos 70, o "desenvolvimento da sociedade de consumo, que condiciona valores e comportamentos sociais ligados ao modo de vida impulsionado pelo reino dos objetos, do conforto e lazer de massa, pano de fundo para o surgimento de uma nova cultura urbana" (GOMES, 2000, p.67).

Nos acalorados discursos oficiais, a ideia firmada no sucesso de um projeto moderno que viesse a vencer o atraso brasileiro esbarrou em uma estrutura ultrapassada. Nesse embate, viu-se a fragmentação "individualista do corpo social, que redundou no consumismo privado, na retração individualista, na atomização dos seres, no hedonismo, no narcisismo, na esterilização das crenças e dos dogmas comuns" (GOMES, 2000, p.67).

Como consequência, o que ocorreu foi o cruzamento de elementos comuns que culminaram na crise que refletiu na cacofonia da cidade (cf. GOMES, 2000), em que a miséria, a degradação e a alienação se acentuaram devido ao descaso dos governantes. Como resultado disso, teve-se a erosão das sociabilidades, a desestabilização de um homem vazio de ideologias e ideais, como também o crescente índice de corrupção e, no ápice da violência, o crescimento assustador do consumo e tráfico de substâncias psicoativas.

No contexto da narrativa brasileira, a partir de 1980 os escritores produziram uma ficção que colocou à margem o registro dos costumes, optando, assim, em representar a instabilidade urbana da cidade enquanto lócus da incerteza e imprevisibilidade. Esta cidade assoma como:

[m]orada incerta que é um "agora" precário a ser substituído por outro agora igualmente precário, quando a modernidade perde fé em si mesma e o presente faz a crítica do futuro e passa a desalojá-lo, e ganham força os conflitos de ordem cultural. (GOMES, 2000, p.68)

A narrativa produzida no Brasil moderno é quase toda urbana e comporta duas dimensões indissociáveis. Níncia Ribas Borges Teixeira comenta que a cidade é, por um lado, 
"o sítio da ação social renovadora, da transformação capitalista do mundo, e por outro lado, a cidade torna-se, ela própria, o tema e o sujeito das manifestações culturais e artísticas" (TEIXEIRA, 2007, p.47). Contudo, ao tentar representar a cidade e o tipo humano que nela vive, não há para o escritor uma representação segura da sociedade diante da velocidade das mudanças sociais, políticas, geográficas e econômicas.

No romance contemporâneo, a descrição das cenas da vida urbana, a heterogeneidade nos discursos e atitudes, os rostos atônitos diante da violência e do medo, o desejo de retornar à cidade ideal, o trabalho da memória, do desejo, do sonho, da esperança rara, desvelam o sentido contraditório e fugaz de viver na cidade. Nesta perspectiva, as representações da cidade na narrativa são evidenciadas por textos que lêem o espaço urbano de modo caleidoscópico, como faz Rodrigo Lacerda ${ }^{1}$ no romance Outra vida, publicado em 1999.

Outra vida traz em sua tessitura a não possibilidade de um acordo entre indivíduo e seu espaço social. Sobre esta questão emblemática, Arlenice Almeida da Silva (2006) observa em "O símbolo esvaziado: a teoria do romance do jovem György Lukács", que na modernidade o indivíduo tornou-se um ser problemático e o mundo tornou-se contingente, em que "não há mais totalidade espontânea do ser" (SILVA, 2006, p.6), ela é oculta, fugidia. A forma romance anuncia essa situação de completo desterro. Na modernidade os homens não cessam de almejar a totalidade perdida. Se antes a totalidade era espontânea, imediata, agora ela é artificial, produtora: ao mesmo tempo desejo, ausência e signo de um desmoronamento.

Na constatação de Lukács, o romance é a forma necessária numa época que se caracteriza pela consciência da cisão e pela incontornável necessidade da busca do sujeito em encontrar um sentido em seu mundo. Assim ocorre com as personagens de Outra vida, que convivem com a sensação permanente de desabrigo da alma, como refere Silva (2001, p.30), quando expressa que o romance moderno é uma construção problemática, "emblema de uma modernidade que perdeu o sentido da vida".

As considerações de Silva, que tem por base a obra A teoria do romance (2000) de Lukács, são oportunas para que se leia a narrativa de Lacerda no viés da impossibilidade da realização de desejos e aspirações do indivíduo na conturbada e precária cidade moderna. Lukács, ao teorizar a respeito do romance moderno, entende que o romance é a forma que casa perfeitamente com os pressupostos da modernidade, em que a apreensão moderna sentimental da natureza não mais mostra que o mundo para o herói não é mais um lar, e sim

\footnotetext{
${ }^{1} \mathrm{O}$ carioca Rodrigo Lacerda é escritor, historiador, editor e tradutor. Além de Outra vida, o escritor publicou mais duas obras, O mistério do Leão Rampante (1995) e A Dinâmica das Larvas: Comédia Trágico-Farsesca (1996).
} 
uma prisão (cf. LUKÁCS, 2000, p.60). A modernidade se caracteriza, portanto, nesta consciência da ruptura com o total, com o absoluto, com a natureza.

Assim, o romance de Lacerda, ao mostrar esta ruptura com a totalidade e com o absoluto, denuncia a "fratura e a dissonância que a acompanha, e desloca o campo de tensão, passando a operar em um plano simbólico esvaziado, mas que continua objetivando a uma totalidade que fará dele a forma épica necessária de nossos dias” (SILVA, 2006, p.02). Nesse sentido, a narrativa caracteriza a oposição entre realidade e ideal, traduzida na tensão entre o desejo e a impossibilidade de realização.

Outra vida apresenta em sua tessitura elementos que permitem que se faça uma leitura crítica voltada aos elementos que denotam o sentido individualista de ver e pensar o mundo por parte das personagens. Tal postura concorre para que se evidencie relações que assumem um caráter de coisas, a uma exponencial mudança de valores, relegando o sujeito à condição de objeto, colaborando, sobremaneira, para sua desumanização.

A narrativa tem como espaço a cidade e problematiza a experiência urbana na modernidade, em que a vivência do choque, a fragmentação das relações pessoais e interpessoais e as contradições próprias do universo moderno caracterizam o itinerário do homem. O romance narra o amanhecer conturbado de uma família - pai, mãe e filha - que esperam na rodoviária de uma grande cidade o ônibus que os levará para uma "nova vida", para a mesma cidade do interior de onde vieram anos antes.

Na metrópole, a existência não é mais possível. Muitos são os fatores que vão contra a permanência da família. O principal motivo deve-se ao fato de que o marido ${ }^{2}$, ex-funcionário de uma estatal, que fora pressionado por seu superior e por necessidades financeiras, quebrou seu código de conduta. Acuado, perseguido e processado, ele resolve ajudar nas investigações e faz sua mea culpa, acreditando que a vida numa cidade pequena possa trazer a tão ansiada redenção: o resgate de sua dignidade.

Porém, enquanto esperam dentro da rodoviária, ao amanhecer, o narrador coloca o leitor frente à problemática maior do sujeito em meio à sociedade, que é o forte apelo ao individualismo que caracteriza os corações urbanos. Esta problemática é instaurada quando a mulher, que criou raízes profissionais e sentimentais na capital, se questiona sobre a fortaleza do casamento e desconfia, principalmente, que a salvação da questão conjugal não estava no retorno da família a uma pequena cidade do interior do estado.

\footnotetext{
2 No romance as personagens que compõem a tríade familiar são nomeadas tão somente como mulher/esposa/mãe, homem/marido/pai, filha/menina. Para tanto, na análise usaremos estes nomes em itálico para denominar as personagens, a fim de situar o leitor.
} 
No box da rodoviária, a mulher, bela e sensual, entende que "o marido, sem dúvida, reaprenderá a conviver com as raízes, a mulher deduz com uma ponta de desprezo" (LACERDA, 2009, p.37), em que tudo se resolveria num banho de sentimentalismo. Irônica, ela sabe que "até o próximo pecado, ele seria um bom convertido, com sua mania de ler a Bíblia e de recitar pílulas de sabedoria” (LACERDA, 2009, p.37). Sua ironia se assenta numa base racional, pois no campo sentimental a vida na metrópole lhe impôs desafios. Entre os desafios, tem-se as dificuldades financeiras, um marido que não aspirava a avanços e sucesso na carreira, um marido "mole", como ela mesmo o denominava quando estava insatisfeita com a falta de perspectiva que ele lhe transmitia.

Diante do comodismo do marido e do fato de que a cidade "não lhe dá tanto dinheiro quanto prometia, e nem chances tão amplas de conhecer as coisas, ou acesso de tudo de bom que via outras pessoas terem" (LACERDA, 2009, p.43), ela se tornou amante do chefe do seu marido.

Silenciosa, em pé num canto da lanchonete, ela observa seu marido que faz dormir a filha de cinco anos em seu colo. Recordando dos últimos conflitos conjugais, a mulher reflete sobre os acontecimentos que culminaram no inevitável retorno da família à cidade pequena. Entre desejar saber o que difere o marido do amante, ela se questiona:

O que faz um homem ser melhor que outro?, a mulher gostaria de saber. A constância de um marido, a eletricidade de um amante ou a promessa misteriosa dos desconhecidos? O que compõe o caráter de um homem, e qual sua real importância para a vida cotidiana? (LACERDA, 2009, p.40)

As divagações da mulher são lançadas na página do romance que é a página da própria vida contingente do sujeito. A narrativa contemporânea sintetiza a "melancolia, desintegração, dissolução, incompatibilidade, abismo entre pensamento e vida, fratura entre as exigências da inteligência e as da ação" (SILVA, 2006, p.05). Outra vida é um exemplo claro deste abismo instaurado, em que tanto o pensamento como a realidade estão degradados. Um romance que coaduna com as ideias de Silva, ao afirmar que a narrativa é “um 'ato simbólico' de expressão da cisão. Uma expressão da insuficiência, de estranhamento, diante da distância entre o eu e o mundo" (SILVA, 2006, p.05).

Esta distância entre o sujeito e seu meio social é percebida por Marshal Berman (1990) ao refletir sobre as mudanças que caracterizam a modernidade. Para ele, esta experiência é paradoxal, uma unidade de desunidade, que "despeja a todos num turbilhão de permanente desintegração e mudança, de luta e contradição, de ambiguidade e angústia" (BERMAN, 1986, p.15). 
A personagem mulher rememora sua vida à época que morava numa cidade pequena. Lá, "seu mundo era menos racionalista; nele o indivíduo não era a medida de todas as coisas, a família instaurava, na vida de cada um, o princípio do coletivo" (LACERDA, 2009, pp.556). Porém, a metrópole cerceia a autonomia dos sujeitos, anulando-os, e faz com que a mulher divague sobre a possibilidade da separação e ganhar seu sustento no espaço urbano capitalista.

Outra vida também expõe as agruras do mundo administrado. O narrador onipresente divaga acerca dos modos hierárquicos que comandam o mundo do trabalho, que não possibilitam a libertação das amarras que condicionam o sujeito às frias relações empregatícias, calculistas e vazias de humanidade:

A cidade, incompatível com qualquer atuação regeneradora, libertadora do tempo, da hierarquia, pois sempre alguém está acima, mandando em você, dispondo de você, ou abaixo, invejando você, querendo o que é seu. (LACERDA, 2009, p.154)

A racionalidade técnica e instrumental, força motriz da sociedade industrial burguesa, anula o sujeito, subjugando-o ao sistema. Para Adorno e Horkheimer, com a anulação, ao passo que a maquinaria do pensamento subjuga o sujeito, tanto mais cegamente ele se contenta com essa reprodução. É nesta seara que entra o poder do aparelho econômico, que antes mesmo do planejamento total, já provê as mercadorias dos valores que decidem sobre o comportamento dos homens (cf. ADORNO; HORKHEIMER, 1985).

Em Outra vida, percebe-se que a cidade impossibilita ao sujeito sua regeneração e sucesso, pois "[...] a vida numa escala grande demais, numa cidade faminta de água, da terra, do subsolo, do ar, e tudo cortando e engolindo" (LACERDA, 2009, p.154), tornara-se impossível segundo a mulher. Esta constatação da personagem reforça o que Berman expõe sobre a ocorrência de um mal-estar coletivo que toma a consciência dos sujeitos, pois vivem na modernidade nada mais do que "uma vida de paradoxo e contradição" (BERMAN, 1990, p.13).

Na narrativa são evidenciadas as transformações sucessivas no espaço físico, os modos de vida que mudam abruptamente e não permitem a sequenciação da experiência que fomenta o sentimento de pertencimento. A personagem homem recorda que tentou viver na metrópole dentro dos padrões éticos e morais que teve como experiência legitima quando morava numa cidade do interior, mas, ao ouvir a proposta de suborno do chefe, aceita o suborno, com a fixa ideia de que o dinheiro poderia ser útil para viver dentro dos padrões que o capitalismo postula.

O romance de Lacerda traz a representação das imagens de uma cidade sem perspectivas e tomada de imprevisibilidades, pois as personagens são impelidas a seguir em 
frente, cegamente, completando o itinerário traçado pelo sistema capitalista que vê a todos como mera engrenagem de uma máquina. Ainda que relutantes, mulher e homem precisam começar de novo, contentando-se com o pouco que o futuro lhes oferece.

Com a emergência do capitalismo industrial e o crescente urbanismo, as fracas experiências dos indivíduos dentro das grandes cidades têm se revelado como um dos temas dominantes da literatura moderna (cf. SIMON, 2006). Esta problemática é amplamente discutida em Outra vida. A cidade é o cenário onde os conflitos da realidade contingente são experimentados com mais intensidade. O marido sucumbe ao suborno oferecido pelo chefe, pois "a cobrança dentro de casa, a revolta surda contra o chefe e o desânimo com o emprego foram envenenando-o, turvando sua capacidade de ser feliz" (LACERDA, 2009, p.58). Por isso, acabou cedendo à indecorosa proposta.

Ainda que estivesse indeciso diante da proposta, "sua revolta foi se revelando proporcional à vontade subterrânea de ganhar dinheiro, farto e fácil, uma turbina de liberdade girando cada vez mais rápido" (LACERDA, 2009, p.66), e cede, dando o último lampejo de lucidez para, então, mostrar-se degradado. Esta passagem vem ao encontro do exposto por Michel de Certeau ao dizer que a cidade é o lugar onde o sujeito e a multidão se mobilizam sob o olhar, é um espaço que "se modifica em texturologia onde coincidem os extremos da ambição e da degradação" (CERTEAU, 1994, p.169).

A personagem homem mostra seu aviltamento quando não sente remorso do seu ato imoral, movido pela ambição. Na narrativa, lê-se que o homem "conviveu com o dilema e o remorso antecipado por algum tempo" (LACERDA, 2009, p.66), mas logo compreendeu que precisava correr o risco. Pouco a pouco, ele monta o dossiê que fora solicitado pelo corruptor, repetindo para si mesmo, a fim de convencimento e isenção de qualquer culpa, que sua atitude não traria prejuízo às pessoas de boa índole, pois "o contribuinte não levaria por culpa sua nenhum prejuízo. Ele apenas recebia um "por fora' para cumprir a técnica função" (LACERDA, 2009, p.66).

A postura do homem denota a alienação do sujeito no âmbito da cidade moderna. Atento a esta questão, André Bueno, explica que a alienação:

[...] designa muito da experiência urbana, moderna e contemporânea. Pode ser, e tem sido usado para indicar as crises e os conflitos de sujeitos sociais cindidos, fragmentados, sem raízes, à deriva, muitas vezes anônimos e expostos à violência de uma vida cotidiana burocrática e impessoal, que parece ir muito além de qualquer entendimento ou controle humanos. (BUENO, 2000, p.89)

Alienado, o homem crê cumprir apenas uma função técnica, isenta de empenho humano, apenas uma ação baseada na racionalidade técnica operada pelos modos de ser e agir 
dentro da sociedade capitalista. A atitude do homem segue a esteira do pensamento de Theodor Adorno (1994, p.68) ao expressar que a reificação que subjuga o indivíduo concorre sobremaneira para sua alienação. O homem é convertido num apêndice da máquina, submetendo-se ao jugo do mercantilismo, em que cada ação sua projeta apenas o lucro financeiro.

Para referenciar a submissão do sujeito moderno à racionalidade instrumental e técnica da sociedade industrial burguesa, Adorno e Horkheimer lançam mão da passagem da epopeia de Homero, Odisséia. No texto homérico, a personagem Ulisses se prende ao mastro da embarcação para não ser arrastado pelo canto das sereias. Assim, ele segue seu curso que é o caminho da obediência e do progresso cego. Os remadores não ouvem o canto das sereias porque estão ligados à sua função, o que denota a reificação e a dominação e não a emancipação, pois "alertas e concentrados, os trabalhadores têm de olhar para frente e esquecer o que foi posto de lado" (ADORNO; HORKHEIMER, 1985, p. 9).

O romance do escritor carioca exprime o que T. Pellegrini expressa sobre a literatura contemporânea. Para ela, a narrativa revela um espaço urbano ficcionalizado que abriga significados novos, e amplia, de modo gradativo, o seu espectro simbólico. De cenário que funcionava apenas como pano de fundo para idílios e aventuras, a cidade pouco a pouco, foi se transformando numa possibilidade de representação dos problemas sociais, até se metamorfosear num complexo corpo vivo, de que os habitantes são a parte mais frágil (cf. PELLEGRINI, 2001).

A raiz de Outra vida reside na atitude irônica do narrador em oscilar entre condições extremas, entre casos-limite, avaliando entre um e outro, entre o certo e o errado. $\mathrm{Na}$ narrativa, o amante da mulher chega à rodoviária, e enquanto se dirige ao box de embarque, reflete acerca dos opostos que demarcam o caráter do homem e da mulher. Para o amante, a mulher é uma ambiciosa assumida, ele, o marido, um ambicioso envergonhado.

A reificação do sujeito dentro da esfera da sociedade moderna é apontada na narrativa quando o amante traz a lume uma comparação entre sua amante e o esposo dela. Irônico em sua comparação, o amante compara ela e seu esposo ao sistema capitalista brasileiro e americano:

É como se o marido fosse o capitalismo brasileiro, com seu complexo de culpa, e a mulher o modelo americano, sem medo de ser feliz; ele, na vida, é o lobista tupiniquim, cuja atuação, por hipocrisia, não está sujeita a lei nenhuma, ela é o lobista dos países desenvolvidos, um profissional como outro qualquer [...] Ele é o atraso patrimonialista, sugador, demagógico, ela, o choque de competitividade saudável que faz os povos e os indivíduos andarem para frente. (LACERDA, 2009, p.89) 
Claramente, percebe-se que o amante denigre a imagem do seu opositor. Esta atitude denota a relação social que assume a forma fantasmagórica de uma relação entre coisas, como expôs Karl Marx (1988), ao descrever as relações fetichistas operadas pelo capitalismo moderno. A mulher entra, pois, num jogo de disputa, como se fosse um objeto de consumo.

Nas passagens em que é apresentada a personagem mulher envolta em pensamentos acerca dos interesses comuns aos conjugues, percebe-se o discurso sobre a ausência que a vida instaura. É a voz de um discurso amoroso ligado a "uma extrema solidão" (BARTHES, 2001, p.11). Esta solidão extremada é revelada quando ela denuncia que "faltava à sua união uma base de interesses mais comuns, capaz de levá-la adiante; só a filha não era suficiente" (LACERDA, 2009, p.137).

A indefinição do sujeito é uma das características da reificação. No romance, a mulher pergunta a si mesma: "E se casasse com o amante, seria feliz?" (LACERDA, 2009, p.36). Alternando dúvida e insegurança, ela segue questionando: "que mulher, com uma filha de colo, larga um casamento para a vida inteira e por um amante? Que mulher faria isso?" (LACERDA, 2009, p.36). Esta indecisão leva a personagem a ter seu eu tripartido, divido entre a tradição, a modernidade e a vulgaridade. Para ela, "as atrizes, modelos, putas e cantoras de quinta categoria expõem-se por completo" (LACERDA, 2009, p.36); já ela não, ainda que tenha um caso extraconjugal, algo do caráter que a moldou na pequena cidade está conservado. Por isso,

As vezes sentia-se na tripla encruzilhada entre o modelo patriarcal, a mulher realmente moderna e a mulher vulgarizada, disposta a tudo, e especulava se não seria essa indefinição a causa dos seus problemas. (LACERDA, 2009, p.45)

A personagem representa esta angústia e indefinição que marca o caráter do homem na metrópole. A personagem mulher é movida pelo desejo que alterna busca por saídas para a crise no casamento e para as dúvidas: ficar na capital ou partir para o interior?

$\mathrm{Na}$ visão de Gomes, a cidade grande materializa a história do sujeito envolto por desafios do mundo contingente. Para o autor, a narrativa contemporânea é o relato sensível das formas de ver a cidade que o escritor possibilita em sua representação,

[...] não enquanto mera descrição física, mas como cidade simbólica, que cruza lugar e metáfora, produzindo uma cartografia dinâmica, tensão entre racionalidade geométrica e emaranhado de existências humanas. (GOMES, 1994, p.24)

No final da narrativa, a possibilidade de redenção a qual o sujeito pode experimentar é vista nas atitudes do homem. Após violenta discussão com a mulher, pois o segredo acerca do seu amante fora revelado, ele - o homem, o pai -, sabe que deve decidir com qual das duas mulheres deve realmente ficar. Ele precisa optar pelo amor da mulher ou pelo amor da filha. 
Se dependesse dele, a louca combinação de ética do trabalho, ganância e aloprada exorcização via progresso tecnológico e consumo, a multiplicação da onipotência humana via ciência de ponta, o apego de todos que se acham inteligentes a uma idéia de progresso e de superação do bem-estar presente, a louca rotina que a humanidade montou para si mesma, os péssimos valores que, na prática, sustentam a vida contemporânea, a destruição do meio natural, as falsas necessidades, tudo isso iria para a lata de lixo da história, pois tirava a energia do que é realmente preciso para a evolução da espécie. (LACERDA, 2009, p.167)

A constatação do homem expressa o grau da degradação do sujeito na urbe contemporânea. Não obstante, na cidade o consumo, a rotina, o progresso são fatores que demarcam o território das forças de produção do mercado voltado aos valores-de-troca. Sobre isto, Marilena Chauí se posiciona. A autora é enfática ao dizer que as sociedades voltadas à produção de mercadorias e ao consumo desordenado de objetos, que na maioria das vezes são supérfluos, se alinham aos moldes do sistema capitalista, em que a alienação, a reificação e o fetichismo fazem parte de um:

[...] processo fantástico no qual as atividades humanas começam a se realizar como se fossem autônomas ou independentes dos homens e passam a dirigir e comandar a vida dos homens, sem que estes possam controlá-las. (CHAUÍ, 1994, p.21)

A par de tudo que sabe e conhece, o homem sente que o amor que sente em relação à filha é como um sopro épico de vida que poderá trazer redenção à sua existência. Recobrando a passagem bíblica, ele deixa claro que "ainda que eu conhecesse todos os mistérios e toda a ciência, e ainda que tivesse toda a fé, de maneira tal que movesse as montanhas, se não tivesse amor, nada seria" (LACERDA, 2009, p.167). A atitude do pai encontra-se dentro da característica das estratégias de negociação dos novos laços humanos que o sujeito precisa reencontrar para que a vida em coletividade seja possível. Contra os elementos que reificam o indivíduo em sociedade, a saber: a ganância, a rotina maçante e repetitiva, o degredo dos valores morais, as falsas necessidades, a personagem mostra um instante de lucidez no desenvolver da trama.

O final de Outra vida desconhece o happy end sobre o qual a literatura romântica fundou seus romances. A narrativa não foge às vicissitudes da realidade, antes denuncia, proclama, aceita a realidade contingente. Nada de surpreendente para o leitor que sabe que na esteira da modernidade, os laços humanos podem ser rompidos. O desenlace da trama traz a representação de uma realidade em que nada é empurrado para baixo do tapete. E se algum leitor desavisado espera que os três - marido, mulher e filha - embarquem no ônibus e o casal reafirme seus votos de amor e fidelidade, isto não acontece. "Você fica?" (LACERDA, 2009, p.177), pergunta ele com segurança para a esposa, ao passo que ela acena que "sim" com a cabeça, convicta da sua decisão. 
Na manhã pela metade, o ônibus parte da rodoviária. Cada um segue um caminho incerto, em direções opostas. O livro, a última página, um relacionamento que finda, a vida que segue. Nessa perspectiva, as personagens mulher e homem estabelecem os lindeiros que demarcam o imaginário representado por uma cidade que "explode implodindo, se estilhaça como cidade fundindo num magma caótico cada um de seus fragmentos", na feliz expressão de Laymert Garcia dos Santos (2002, p.116).

Indubitavelmente, o leitor encerra a leitura do romance intrigado, repleto de questionamentos e inquietações sobre a representação das imagens da cidade que a obra exprime, que é a condição do sujeito moderno dentro de um cenário urbano caótico, conflituoso, inseguro, imprevisível e instável. Certamente, o leitor se questiona: "Uma outra vida é possível na cidade moderna?".

\section{Fechando as cortinas do cenário da cidade}

A literatura contemporânea elegeu a cidade como lócus de representação, em que não mais temos aquele abrigo comum da epopeia, para onde o herói retornava após suas andanças e lutas, não há mais aquele "lar" para resgatar o sentido da sua vida e restauração da sua existência. Se na epopeia o herói homérico enfrenta as sereias e figuras míticas, as personagens do romance Outra vida transitam por uma cidade em que os traços da modernidade se apresentam aos seus olhos de maneira conflituosa, em que a incerteza e a imprevisibilidade caracterizam o seu modo de ser e agir.

Acerca da relação entre a literatura e a constituição do mundo moderno, Paul Conrad Kurz expressa que a "composição épica de nosso tempo, o romance, está sociológica e psicologicamente em estreita conexão com a perda de uma comunidade de apoio, de uma compreensão abarcadora da fé e do mundo, com a individualização e isolamento do herói” (KURTZ, 1968, p.18). Nestes termos, a obra de Lacerda mostra, através das ações e atitudes de suas personagens, que não há espaço seguro para que sujeito possa idealizar dentro de uma sociedade degradada, repleta de vivências vazias de sentido e perspectivas futuras nulas.

Grosso modo, a leitura e análise de Outra vida vêm ao encontro o que Sandra Jatahy Pesavento pensa a respeito da representação das imagens da cidade na ficção literária. Para ela, a literatura tem produzido representações sobre o urbano e o seu habitante, que traduzem não só as transformações do meio como as sensibilidades e as sociabilidades dos seus agentes (cf. PESAVENTO, 1999, p.13), num diálogo literário que contribui para a recuperação, a identificação, a representação das transformações no sujeito dentro da sociedade moderna. De 
modo claro, o romance, objeto de estudo, se insere no rol das obras literárias que tem na cidade seu objeto de representação.

\section{Referências}

ADORNO, Theodor. Capitalismo tardio ou sociedade industrial. In: Gabriel Cohn). 2. ed. São Paulo: Ática, 1994. Sociologia. (Org.

ADORNO, Theodor; HORKHEIMER, Max. O conceito de esclarecimento. In: Dialética do esclarecimento: fragmentos filosóficos. (trad. Guido Antonio de Almeida). Rio de Janeiro: Jorge Zahar Ed., 1985.

BARTHES, Roland. Fragmentos de um discurso amoroso. Rio de Janeiro: Francisco Alves, 2001.

BERMAN, Marshall. Tudo que é sólido desmancha no ar: a aventura da modernidade. 8. ed. São Paulo: Schwarcz, 1990.

Tudo que é sólido desmancha no ar: a aventura da modernidade. (Trad. Carlos Felipe Moisés; Ana Maria L. Ioratti). São Paulo: Companhia das Letras, 1986.

BUENO, André. Sinais da cidade: forma literária e vida cotidiana. O imaginário da cidade. (Rogério Lima e Ronaldo Costa Fernandes orgs.) Brasília: Editora Universidade de Brasília: São Paulo: Imprensa Oficial do Estado, 2000.

CHAUÍ, Marilena. O que é ideologia. São Paulo: Brasiliense, 1994.

GOMES, Renato Cordeiro. Cartografias urbanas: representações da cidade na literatura. Semear, n. 1, 2000. Disponível em: http://www.letras.puc-rio.br/catedra/revista /1Sem_12.html. Acesso em: 14 fev. 2012.

KURZ, Paul Conrad. Metamorfosis de la novela moderna. In: Madrid: Guadarrama, 1968. La nueva novela europeia.

LACERDA, Rodrigo. Outra vida. Rio de Janeiro: Objetiva, 2009.

LUKÁCS, Georg. A teoria do romance. São Paulo: Editora 34, 2000.

MARX, Karl. Fetichismo e reificação. In: . Sociologia. São Paulo: Ática, 1988.

PELLEGRINI, T. A ficção brasileira hoje: os caminhos da cidade. Revista de Filología Románica. Vol. 19, 2002. Disponível em: http://revistas.ucm.es/index.php/RFRM/article/ view/RFRM0202110355A. Acesso em: 26 març. 2012.

PESAVENTO, Sandra Jatahy. O imaginário da cidade: visões literárias do urbano: Paris, Rio de Janeiro, Porto Alegre. Porto Alegre: UFRGS, 1999.

POE, Edgar Allan. O homem na multidão. In: BAUDELAIRE, Charles. O pintor da Vida moderna. (Concep. e org. Jerome Dufilho e Tomaz Tadeu. Trad. Tomaz Tadeu). Belo Horizonte: Autêntica, 2010. 
RICOEUR, Paul. Interpretação e Ideologias. (Org. Hilton Japiassu). 4. ed., Rio de Janeiro: Francisco Alves, 1983.

ROCHA, Rejane C. A Forma do Real: a representação da cidade em Eles eram muitos cavalos. XII Congresso Internacional da ABRALIC. 18 a 22 de julho de 2011. Brasil, Curitiba: UFPR, 2011. Disponível em: http://www.abralic.org.br/anais/cong2011/ AnaisOnline/resumos/TC0128-1.pdf. Acesso em: 24 mar. 2012.

SANTOS, Laymert Garcia dos. São Paulo é mais ima cidade. In: PALLAMIN, VAERA; LUDEMANN, Marina orgs. Cidade e cultura: esfera pública e transformação urbana. São Paulo: Estação Liberdade, 2002, p. 116.

SILVA, Arlenice Almeida da. O símbolo esvaziado: a teoria do romance do jovem György Lukács. Revista Trans/Form/Ação, São Paulo, 29 (1): 79-94, 2006, p.2. Disponível em: http://www.scielo.br/pdf/trans/v29n1/ 30283.pdf . Acesso em: 20 jan. 2012.

Da Teoria do Romance ao Romance Histórico: a questão dos gêneros em G. Lukács. Rapsódia. São Paulo, v. 01, p. 29-53, 2001, p.30.

SIMON, Iumna Maria. Linguagem poética e crescimento urbano-industrial. Revista Letras. São Paulo, v. $46, \quad$ n. $1, \quad$ p. 127-150, jan.-jul., 2006. Disponível em: http://seer.fclar.unesp.br/letras/article/view/44. Acesso em: 21 març. 2012.

TEIXEIRA, Níncia Cecília Ribas Borges. Fisionomia da cidade moderna: imagens literárias modernas. Terra Roxa e outras terras - Revista de Estudos Literários. Vol. 10, 2007. Disponível em: http://www.uel.br/pos/letras/terraroxa/g_pdf/vol10/10_5.pdf . Acesso em: 26 març. 2012. 